\title{
INFANTS WITH NEONATAL ENCEPHALOPATHY TRANSPORTED FOR THERAPEUTIC HYPOTHERMIA - ADHERENCE TO STANDARD COOLING CRITERIA
}

\author{
S. Mohinuddin ${ }^{1,2}$, R. Mohidin ${ }^{3}$, N. Ratnavel ${ }^{1,2}$, A. Sinha ${ }^{2,3}$, D. Shah ${ }^{2,3}$
}

${ }^{1}$ London Neonatal Transfer Service, Barts and The London NHS Trust, ${ }^{2}$ Department of Neonatology, Barts and The London Children's Hospital, Royal London Hospital, ${ }^{3}$ School of Medicine, Barts and The London

School of Medicine and Dentistry, Queen Mary College, London, UK

Background and aims: There is increasing evidence that therapeutic hypothermia may improve survival and reduce the rate of disability in infants with neonatal encephalopathy. The aim of this study was to evaluate the referrals for cooling received by London Neonatal Transfer Service (NTS) and assess their adherence to the enrolment criteria used by the TOBY study (Azzopardi et al NEJM 2009).

Methods: Prospective data collected for referrals from January 2007 to August 2010.

Results: 103 transfers of passively cooled newborns were undertaken. Median (range) values for gestation were 40 (35-42) weeks, birth-weight $3.28 \mathrm{~kg}$, age at referral 3:53 (01:47 - 08:55) hours and age at arrival to cooling centre was 6:55 (03:52 - 12:44) hours.

Three infants were less than 36 weeks gestation and 9 didn't meet any of the other TOBY criteria A shown in table.

\begin{tabular}{|l|c|}
\hline Criteria A - Gestational age $\geq 36$ & 100 \\
\hline Apgar score $\leq 5$ at 10 minutes after birth & 42 \\
\hline $\begin{array}{l}\text { Continued need for resuscitation at } 10 \text { minutes after } \\
\text { birth }\end{array}$ & 73 \\
\hline $\mathrm{pH}<7.00$ within 60 min of birth & 60 \\
\hline Base deficit $\geq 16 \mathrm{mmol} / \mathrm{L}$ within 60 min of birth & 49 \\
\hline
\end{tabular}

[Adherence to TOBY criteria. $N=103$ ]

Except for clinical seizures, noted in 52\% of referrals, documentation of the B criteria (neurologic assessment of encephalopathy) were difficult to assess from the documentation.

Conclusions: Most neonatal transfers for cooling by London NTS fulfilled the TOBY criteria A . Our study highlights a need for greater attention to neurologic examination and improved documentation of findings for infants referred for cooling. 